\title{
Antonio Huertas Morales (dir.), Edad Media Contemporánea. Valencia: Universidad de Valencia, 2017, 205 págs.
}

Edad Media Contemporánea es una obra colectiva dirigida por Antonio Huertas Morales que vio la luz en formato digital en el año 2017. Su tema principal lo constituyen las reconstrucciones y representaciones de la Edad Media en las distintas formas actuales de producción cultural y de ocio. La publicación se inserta en el Proyecto Parnaseo (Servidor Web de Literatura Española) de la Universidad de Valencia, dirigido por la profesora Marta Haro Cortés, constituyendo el sexto volumen de su publicación Monografías Aula Medieval. ${ }^{1}$ En el marco de este proyecto se encuentra también el portal Storyca: Edad Media Contemporánea, dedicado al estudio del imaginario medieval en la era digital desde una perspectiva multidisciplinar. El tema del libro no es nuevo para Huertas Morales. En 2013 defendía su tesis doctoral, dirigida por la propia Haro Cortés y que fue publicada en 2015 bajo el título de La Edad Media contemporánea. Estudio de la novela española de tema medieval. ${ }^{2}$

A nivel estructural la obra consta de doce trabajos que podemos agrupar en cuatro bloques o núcleos atendiendo a su contenido:

a) El primero está compuesto por cuatro estudios dedicados al tratamiento de cuestiones varias sobre la presencia y reconstrucción de lo medieval en la literatura contemporánea.

b) Tras ello encontramos dos artículos dedicados a la representación del medievo en la música y concretamente en el género del Heavy Metal.

c) En tercer lugar, se identifica un bloque más heterogéneo en el que se estudia la representación del imaginario medieval en diferentes formas de producción cultural actuales como el teatro, los videojuegos, el cómic y el cine.

d) Para terminar, el libro se cierra con un trabajo que nuevamente nos introduce en la reconstrucción del pasado medieval a través de la novela contemporánea.

Abriendo el primer bloque encontramos el trabajo de Luis García Jambrina, ${ }^{3}$ que explica la forma en que él mismo representa la Edad Media en sus obras El manuscrito de piedra y El manuscrito de nieve. Se trata de dos novelas negras ambientadas en la Salamanca del siglo XV y cuyo protagonista es Fernando de Rojas, autor de La Celestina. García Jambrina explica cómo recurre a la estructura de la novela negra para introducir al lector

\footnotetext{
${ }^{1}$ Sobre la actividad y la estructura del Proyecto Parnaseo véase: Marta Haro Cortés, "Parnaseo (Servidor Web de Literatura Española)," Historias Fingidas, 7 (2019): 437-442.

2 Antonio Huertas Morales, La Edad Media contemporánea, estudio de la novela española de tema medieval (1990-2012) (Vigo: Academia del Hispanismo, 2015). Cuenta, además, con otras publicaciones sobre este tema en diferentes revistas.

${ }^{3}$ Luis García Jambrina, "Naturalmente, dos manuscritos: dos novelas históricas sobre el final de la Edad Media en Salamanca," Monografías Aula Medieval, $6 \quad$ (2017): 04-13.
} 
en el contexto histórico y explicarlo con la mayor veracidad posible. Según observa, para ello es necesaria una profunda labor de documentación previa sobre el periodo y el espacio abordados. Sólo así se puede lograr la inmersión histórica del lector, superando la ambientación histórica de la novela como simple contexto de la trama, de modo que el producto resultante sea a la vez entretenido e instructivo.

En segundo lugar, Raquel Crespo-Vila ${ }^{4}$ estudia la reactualización de la literatura medieval en la novela contemporánea a partir de los conceptos de intertextualidad e hipertextualidad. Partiendo de una comprensión del presente como una contemporaneidad posmoderna, entiende que la actualidad es el momento de la historia de la literatura que mejor define el concepto de intertextualidad. Habiéndose producido una completa transformación del concepto de originalidad, cada nueva obra se construye de forma más o menos indisimulada sobre el sustrato de otras obras anteriores. En una aplicación retrospectiva de esta idea observa cómo la recuperación y reelaboración de temas, personajes y mismo de fórmulas y recursos literarios de la literatura medieval se puede comprender como la fusión de los fenómenos de la intertextualidad y la medievofilia contemporánea. A partir de casos concretos como el Cid, la Celestina o El libro del buen amor, observa diferentes formas de intertextualidad que la llevan a cerrar su exposición invitando a la reflexión sobre "cuan original es no ser original". 5

El tercer trabajo que encontramos es el del propio Antonio Huertas Morales, ${ }^{6}$ quien analiza la reciente eclosión del libro digital como formato preferido para la publicación de novelas históricas. Para ello se centra en el análisis de la narrativa histórico-medieval en el Kindle Direct Publishing de Amazon. Su estudio va más allá del análisis de los procesos y los fenómenos de edición, reflexionando también sobre las características y las transformaciones del mundo de la lectura en la era digital. La elección del caso de Amazon como objeto de estudio se debe a que ha destacado, con diferencia, como el principal editor-distribuidor de libros digitales. Entre las principales consecuencias de esto se observan la proliferación de títulos publicados, la reducción generalizada de su extensión y el mayor grado de imperfección del resultado final. Sobre esto último, Huertas Morales pone el acento en el hecho de que Amazon no fija los textos de forma definitiva, sino que permite modificarlos después de haber sido publicados bajo la idea de "work in progress". A partir de ahí, la reflexión del autor se cierra apuntando la "volatilidad de los contenidos" textuales en la era digital. ${ }^{7}$

Anabel Sáiz Ripoll cierra el primer bloque de trabajos con un estudio sobre la presencia del Cid como prototipo de héroe medieval en la literatura infantil y juvenil española. ${ }^{8}$ Comienza con la exposición de algunos datos sobre las características del

\footnotetext{
${ }^{4}$ Raquel Crespo-Vila, "La literatura medieval en la narrativa contemporánea," Monografías Aula Medieval, 6 (2017): pp. 14-25.

${ }^{5}$ Raquel Crespo-Vila, "La literatura": 23.

${ }^{6}$ Antonio Huertas Morales, "Del scriptorium a la red: Amazon y la narrativa española de tema medieval," Monografías Aula Medieval, 6 (2017): 26-45.

${ }^{7}$ Antonio Huertas Morales, "Del scriptorium": 41.

${ }^{8}$ Anabel SÁIZ RIPOLL, "El Cid: la actualidad de un mito (reflexiones en torno al Cantar y su presencia en la literatura infantil y juvenil," Monografías Aula Medieval, 6 (2017): 46-59.
} 
Cantar de mío Cid desde su gestación hasta época moderna. A continuación, se estudian y comentan varios títulos infantiles y juveniles que versan sobre el relato cidiano. A partir de ahí se observa cómo su figura literaria, que no la figura histórica, se configura como el prototipo de héroe medieval que acumula atributos positivos. Se produce, así, un desplazamiento de la imagen del noble rebelde por la del vasallo que actúa de forma correcta a pesar de haber sido injustamente tratado. La generalización de esta representación en la literatura infantil y juvenil provocaría una reconstrucción de un aspecto concreto de la Edad Media que, pese a ser parcial, pasaría a integrarse en el imaginario colectivo.

En el segundo bloque nos encontramos dos trabajos sobre la presencia del imaginario medieval en las letras de algunas canciones de Heavy Metal en castellano. Pablo Escoto Pérez ${ }^{9}$ realiza un estudio de la representación de temas, personajes y acontecimientos medievales en algunas canciones españolas. A través de su estudio se puede observar cierta dualidad en el reaprovechamiento de la temática medieval. Por un lado, se identifica un sector del Heavy Metal español que recurre a una caracterización heroica y tópica de cuestiones como la guerra contra los musulmanes y de personajes como el Cid o don Pelayo. Por el otro, se aprecia también una reactualización de temáticas e ideales medievales bajo una perspectiva contemporánea, generando críticas antibelicistas, feministas y en contra de la opresión sexual y religiosa.

En una línea similar, Amaranta Saguar García se centra en el análisis de la representación de la figura histórica y literaria de el Cid en el Heavy Metal. ${ }^{10}$ Para esto toma como base de estudio diez composiciones de grupos mayormente españoles pertenecientes a diferentes subgéneros de este estilo musical. Su análisis revela una representación generalmente deficiente del Cid como prototipo del caballero medieval hispano sobre el que se tipifican valores heroicos estandarizados. Más allá de esto, el trabajo de Saguar García resulta de gran interés por cuanto analiza el uso de la figura del Cid por parte de cada grupo. Establece así distinciones entre las letras que valorizan el fondo histórico-cultural y literario hispano, las que carecen de significaciones políticas y sociales, y las que persiguen la reivindicación de diferentes identidades nacionales y regionales. Destaca también la identificación de una corriente crítica que demoniza la figura del Cid como parte de una reacción contra la idea de la España heroica y victoriosa de la Reconquista, asociada a sectores políticamente conservadores.

El tercer bloque de trabajos se abre con un estudio de Matija Janeš sobre la reescritura del relato cidiano a partir de tres obras de teatro contemporáneas. ${ }^{11}$ Al igual que hacía Raquel Crespo-Vila más arriba, Janeš retoma las ideas de intertextualidad y posmodernismo para situar el contexto de su análisis. Ante la ausencia total del tópico del heroísmo cidiano, su análisis busca explicar cómo las reconstrucciones teatrales del

\footnotetext{
9 Pablo Escoto Pérez, "Héroes y temas medievales en el heavy metal en castellano," Monografías Aula Medieval, 6 (2017): 60-74.

${ }^{10}$ Amaranta Saguar García, "Presencia del Cid en el Heavy Metal en relación al auge y al declive de algunos de sus subgéneros," Monografías Aula Medieval, 6 (2017): 75-90.

${ }^{11}$ Matija Janeš, "Historia Medieval en tiempos sin historia. Unas propuestas teatrales," Monografías Aula Medieval, 6 (2017): 91-108.
} 
pasado problematizan y deconstruyen el discurso histórico, generando una nueva realidad desde ópticas actuales. En Anillos para una dama (1991) de Antonio Gala, observa como la aplicación de una perspectiva individualista y microhistórica sirve para cuestionar la imagen de una España fuerte, católica y homogénea. En El juglar del Cid (2009) de Pedro Víllora, se subraya la desmitificación existencialista de la figura heroica del Cid, convertido en un personaje al que sobrepasan los acontecimientos de su tiempo. Por último, en Doña Jimena (2008) de Magdalena Lasala, se observa la idealización de un medievo feminista y pacifista, opuesto a las ideas de opresión, masculinidad y violencia que se atribuyen al Cid.

Seguidamente, Daniel Escandell Montiel $^{12}$ presenta un análisis de la reconstrucción y recodificación del imaginario medieval español en el mundo de los videojuegos. Observa que la representación del medievo hispano en esta industria es tenue en comparación a lo que sucede con casos como el británico o el japonés. En lo que se refiere a las iniciativas españolas, la representación del medievo en los videojuegos es escasa, hecho que el autor achaca a cierta incapacidad por promover y mercantilizar el patrimonio nacional. Frente a esto, su estudio refleja un claro predominio de las desarrolladoras extranjeras, que engrosan su comprensión occidentalista de la Edad Media con tópicos bélicos como el de la Reconquista, personajes como el Cid y Pelayo, o seres mitológicos del folclore castellano. Entre estos temas se hace notar la predilección existente por el imaginario cidiano, que ha dado lugar a infrarrepresentaciones fragmentarias y, por lo general, históricamente erróneas.

Jose Pablo Gallo León y María Victoria Játiva Miralles ${ }^{13}$ ofrecen un estudio sobre la presencia de la Edad Media en el mundo del cómic, apuntando las posibilidades de este tipo de publicaciones como recurso didáctico de apoyo para la enseñanza de la historia. Comienzan con una presentación general de la presencia de la Edad Media en el mundo del cómic, que se habría iniciado en 1937 con la publicación del Príncipe valiente de Harold Foster. A partir de ahí plantean una tendencia general hacia la perpetuación de una visión negativa de la época medieval, paralela al desarrollo de tópicos heroicos y caballerescos heredados de la literatura romántica del XIX. Atendiendo al grado de veracidad histórica de los relatos, distinguen entre aquellos que recurren a lo medieval como parte del argumento y los que lo hacen como simple ambientación o decorado. A pesar de que la combinación secuencial de imágenes y texto supone un formato muy útil para la transmisión y asimilación de ideas, se lamenta que el uso del cómic como recurso docente no esté más extendido. Sobre este tipo de premisas se tratan algunos títulos destacados del cómic de trasunto medieval, distinguiendo entre los que contienen reconstrucciones fabulosas y los que muestran un mayor empeño de veracidad histórica.

12 Daniel Escandell Montiel, "Del Cid y la zarrampla: el imaginario caballeresco español en los videojuegos," Monografías Aula Medieval, 6 (2017): 109-123.

13 Jose Pablo Gallo León Y María Victoria Játiva Miralles, "Cómic y Edad Media: del escenario a la didáctica," Monografías Aula Medieval, 6 (2017): 124-138. 
La aplicación didáctica de la investigación también está presente en Juan Antonio Barrio Barrio. ${ }^{14}$ En su trabajo analiza la producción cinematográfica de ambientación histórica medieval en sus diferentes formas (épica, ficción, realismo histórico, etc.) como uno de los principales productos culturales a partir de los que se construye la actual imagen de la Edad Media. Sobre ello nota que la influencia de la tradición literaria se ha mantenido desde el siglo XIX hasta hoy, ejemplo de lo cual serían algunas adaptaciones cinematográficas como la de la Tierra Media de J. R. R. Tolkien y televisivas como la de Game of Thrones. En base a estas consideraciones, el autor presenta una propuesta de utilización del cine como recurso docente, en la que se incluyen un modelo de ficha de estudio, una catalogación de temas y personajes, y una guía de películas de contenido histórico.

Lo que identificamos como el tercer bloque se cierra con el trabajo de Maria Bosch Moreno, quien analiza el uso de la etiqueta \#LiteraturaMedieval en la red social Twitter entre 2010, año de la primera mención, y 2016. ${ }^{15}$ La tipología de los datos cotejados en el estudio de los tweets incluye diferentes variables como la fecha, el tipo de emisor, el tipo de contenido, el idioma y el volumen y el tipo de interacciones generados entre otros usuarios. La observación de los datos obtenidos permite notar cierta superficialidad del contenido generado a partir de esta etiqueta. Existiendo una mayor utilización por parte de perfiles personales que institucionales, su uso roza lo anecdótico sin que se profundice en cuestiones relativas al patrimonio cultural literario medieval.

Para finalizar, el trabajo de Kaia Sisask ${ }^{16}$ conformaría individualmente el cuarto bloque, retomando el tema de la relación entre la edad media y la novela histórica contemporánea. Sisask analiza cómo la identidad nacional de la ciudadanía estonia se refleja en las novelas de detectives de ambientación medieval de Indrek Hargla's. Todas las historias de Hargla's transcurren en la ciudad de Tallinn, que tiene un gran peso simbólico en la construcción de la compleja identidad nacional estonia. El escritor realiza una reconstrucción altamente fidedigna de la ciudad en el siglo XV y la presenta como un espacio urbano pacífico, próspero y tolerante, regido por la razón y la justicia. Sobre ello, Sisask observa que la reconstrucción de Hargla's condiciona, y está condicionada, por la imagen que Estonia ha configurado sobre sí misma. Después de siglos de sucesivas dominaciones por potencias extranjeras que terminaron en 1991 con la disolución de la Unión Soviética, se configura una imagen nacional multicultural caracterizada por valores como la unidad, la diversidad y la tolerancia.

De forma global se aprecia una notable interconexión de los temas tratados por los diferentes autores que participan en el libro. Existe una tendencia general a centrar los estudios en el ámbito del medievo hispano, dentro del cual la materia cidiana es un elemento recurrente en las diferentes formas de producción cultural que se abordan. De

\footnotetext{
${ }^{14}$ Juan Antonio Barrio Barrio, “Cine e Historia. Una aproximación desde una perspectiva docente: la Edad Media,” Monografías Aula Medieval, 6 (2017): 139-170.

15 Maria Bosch Moreno, "La \#LiteraturaMedieval en las redes sociales: Twitter, un punto de partida," Monografías Aula Medieval, 6 (2017): 171-187.

${ }^{16}$ Kaia Sisask, "The golden middle ages in Indrek Hargla's crime novels," Monografías Aula Medieval, 6 (2017): 188-202.
} 
igual modo, se puede observar cierto interés por las aplicaciones didácticas de la investigación, siendo esta una de las preocupaciones principales que dirigen la actividad del Proyecto Parnaseo.

Destaca, también, el uso integrado de las nuevas tecnologías en la configuración interna de la obra. Esta va más allá de la simple publicación en formato digital, haciendo un uso casi parejo de los hipervínculos y de las notas a pie de página. Con ello se adentra en el ámbito del hipertexto, en el que la escritura e Internet se combinan para generar contenidos con un mayor grado de interactividad que el de la publicación en papel.

En definitiva, la aparición de este libro en 2017 se puede comprender como el resultado de la larga colaboración entre Huertas Morales y Haro Cortés en el marco del Proyecto Parnaseo y, de forma más concreta, en el del portal Storyca. En 2018 ambos participaron, junto con otros investigadores como María Bosch, en la presentación de dicho portal en el Coloquio Internacional de la Asociación Hispánica de Literatura Medieval, Libros, lecturas y reescrituras. Así pues, parece que la Edad Media Contemporánea comienza a consolidarse como una línea de estudio sobre las formas y usos del neomedievalismo en la era digital y la producción cultural de masas.

José Ángel Salgado Loureiro

Universidad de Santiago de Compostela

asalgado.loureiro@gmail.com

Fecha de recepción: 1 de mayo de 2020

Fecha de aceptación: 18 de mayo de 2020

Publicación: 1 de julio de 2020

Para citar este artículo: José Ángel Salgado Loureiro, “Antonio Huertas Morales (dir.), Edad Media Contemporánea. Valencia: Universidad de Valencia, 2017, 205 págs.", Historiografías, 19 (enero-junio, 2020), pp. 167-172. 